\title{
What Is the Role of PFTs in Monitoring Adverse Effects of Surgery, Drug Treatments, Radiation Therapy, and During Hospitalization?
}

\author{
Oleh W Hnatiuk MD
}

\author{
Introduction \\ What Is the Role of Spirometry and $D_{\mathrm{LCO}}$ in Hospitalized Patients? \\ Do Physicians Really Alter Treatment and/or Surgery Based on the Results \\ of PFTs? \\ What Is the Evidence Base for Using PFTs for Priority Listing for Solid \\ Organ Transplantation (Kidney, Liver, Lung)? \\ Lung Transplantation \\ Kidney and Liver Transplantation \\ Summary
}

\begin{abstract}
Measurement of various aspects of pulmonary function is a relatively easy, noninvasive, and inexpensive way to gauge the status of the respiratory system. Interest in using these tests to determine risk from medical and surgical interventions stems from their presumed ability to be more sensitive than history or physical examination in detecting underlying lung disease. When coupled with the assumption that early detection of pulmonary abnormalities will lead to alterations in patient management, the ultimate goal of improved patient outcomes becomes very attractive. However, despite advances in technology, achievement of this goal has proved to be more challenging than expected in many areas. This paper attempts to review the literature addressing several of the more difficult of these areas. It is clear that more research, involving more rigorously designed studies, will be necessary, before definitive answers are available. Key words: pulmonary function testing; clinical utility; risk; outcomes. [Respir Care 2012;57(1):75-82]
\end{abstract}

\section{Introduction}

The true value of any medical test is ultimately determined by its ability to assist healthcare providers in improving the well-being of their patients. Simple tests with reproducible values and evidence-based thresholds defining normality and abnormality are relatively easy to interpret. The work that goes into finding these tests, thresholds, and subsequent outcomes is enormous. So when one

Dr Hnatiuk is affiliated with the Pulmonary and Critical Care, Medicine Service, Walter Reed National Military Medical Center, Washington, District of Columbia.

Dr Hnatiuk presented a version of this paper at the 48th RESPIRATORY CARE Journal Conference, "Pulmonary Function Testing," held March 25-27, 2011, in Tampa, Florida. is faced with evaluating tests that are prone to subject technique, operator variability, and ill-defined arbitrary boundaries of normalcy coupled with various reference values and subjective interpretations, the task of deciding the clinical utility of pulmonary function testing becomes rather daunting. Perhaps that is why there is not an overwhelming amount of evidence-based research available in this area from which to make clear-cut recommendations or decisions. This fact is not lost on most experienced, clinically savvy healthcare practitioners, who maintain a

\footnotetext{
The author has disclosed no conflicts of interest.

Correspondence: E-mail: owhmd1 @ verizon.net.

DOI: $10.4187 /$ respcare. 01467
} 


\section{What Is the Role of PFTs in Monitoring Adverse Effects?}

healthy degree of skepticism toward literature that is based on opinions rather than facts. Others embrace following the same guidelines as a way to either acceptable outcomes, or at the least, as a way to show that they are aware of what is expected, and sometimes blindly follow the prescribed path of least resistance. It is likely with this in mind, close to 20 years ago, that Hayhurst commented "a request for preoperative pulmonary function testing has become part of the tradition of investigation of patients due to undergo major surgery ... is made almost on reflex, with little regard for why the tests are indicated ... in these increasingly cost conscious times, an expensive luxury of little clinical usefulness...." And although the amount of knowledge and literature in the areas of pulmonary function testing, therapeutic interventions, and diseases discussed in this review have increased exponentially, in many respects the medical community is no closer to an answer than it was back then.

What is the role of spirometry, diffusing capacity of the lung for carbon monoxide $\left(\mathrm{D}_{\mathrm{LCO}}\right)$, 6-minute walk test (6MWT), or maximal oxygen uptake for predicting risk (for pneumonectomy/lobectomy, lung-volume-reduction surgery [LVRS], non-thoracic surgery, or chemo and radiation therapy)?

Pulmonary function testing is widely used in the preoperative evaluation for resectional lung surgery. The American College of Chest Physicians and the British Thoracic Society have developed algorithmic approaches to the preoperative physiologic assessment of postoperative risk, which incorporates a variety of these pulmonary function tests (PFTs). ${ }^{2,3}$ These algorithms begin with the performance of simple spirometry, and, if necessary, end with performance of the more complex cardiopulmonary exercise test. If cardiopulmonary exercise test is unavailable, the British Thoracic Society guidelines allow for the performance of a shuttle test. In general, as one proceeds down the American College of Chest Physicians algorithm, the number of patients studied to support the recommendations decreases (Fig. 1). And although each of the individual spirometric abnormalities has been associated with either increased perioperative risk or mortality, these algorithms have never been validated prospectively.

Interestingly, despite a substantial number of patients and studies cited in support of these approaches, generally one study contributes the majority of patients at each step. And sound, convincing research methodology is infrequently present in these studies. The largest study referenced in the algorithms was published by Miller in 1993. ${ }^{4}$ This prospective cohort reported on 2,340 patients undergoing a variety of thoracic surgeries for lung cancer from 1974 to 1990 . The surgical mortalities for 5 different types of resection performed on the cardiothoracic surgical service of Emory University-affiliated hospitals were compiled. Operative approach was based on spirometric cut- offs described in literature dating from 1955-1984. Without validation in a separate cohort of patients, the author concluded that, because the operative mortalities in their own patient population were so low (ranging from $0.59 \%$ for exploratory thoracotomy to $4.97 \%$ for pneumonectomy), their approach should be followed for choosing candidates for lung resection. In their discussion, the authors proposed what appears to be the first algorithm for evaluation of preoperative pulmonary function in resectional lung surgery, which included only $\mathrm{FEV}_{1}$ and maximum voluntary ventilation.

The variables used for determining appropriate LVRS candidates were recently reviewed by DeCamp and colleagues. ${ }^{5}$ Spirometric parameters predicting poor outcome included $\mathrm{FEV}_{1} \leq 20 \%$ predicted, and either $\mathrm{D}_{\mathrm{LCO}} \leq 20 \%$ predicted or homogeneous distribution of emphysema on high-resolution computed tomography scan. The methodology in identifying this subgroup was solid. These patients met the predetermined lower 95\% confidence threshold for 30-day mortality of greater than $8 \%$ during the National Emphysema Treatment Trial (NETT). ${ }^{6}$ In this high risk group, the 30-day mortality and overall mortality were significantly higher than the medically treated group. However, at the trial's conclusion, this group was found to have a statistically significant difference in 90-day mortality, but not total mortality. ${ }^{7}$

Other tests of pulmonary function reported to identify good candidates for LRVS are the post-rehabilitation 6-min walk distance greater than $140 \mathrm{~m}$ and low post-rehabilitation exercise capacity (demonstrated by maximal achieved cycle ergometry watts, where low exercise capacity is defined as a post-rehabilitation maximal work load at or below the sex-specific 40th percentile ( $25 \mathrm{~W}$ for women and $40 \mathrm{~W}$ for men) (Table 1). The former was used as a criterion for inclusion in the NETT study, and the latter was found in subgroup analysis at the study's conclusion. According to the authors, the apparent improved survival benefit in this latter group was due to the higher mortality of patients with low exercise capacity in the medical-therapy group.

The utility of preoperative pulmonary function testing in non-thoracic surgery has not been studied extensively. Based upon a systematic review of the literature from 1980 to 2005, written by Smetana and colleagues in 2006, ${ }^{8}$ the American College of Physicians issued a risk assessment guideline attempting to reduce perioperative pulmonary complications for patients undergoing non-cardiothoracic surgery. ${ }^{9}$ The recommendation from this guideline was that "preoperative spirometry should not be used routinely for predicting risk for postoperative pulmonary complications" in non-thoracic surgeries, although it did state that "preoperative pulmonary function testing may be appropriate in patients with a previous diagnosis of chronic obstructive pulmonary disease or asthma." The authors 


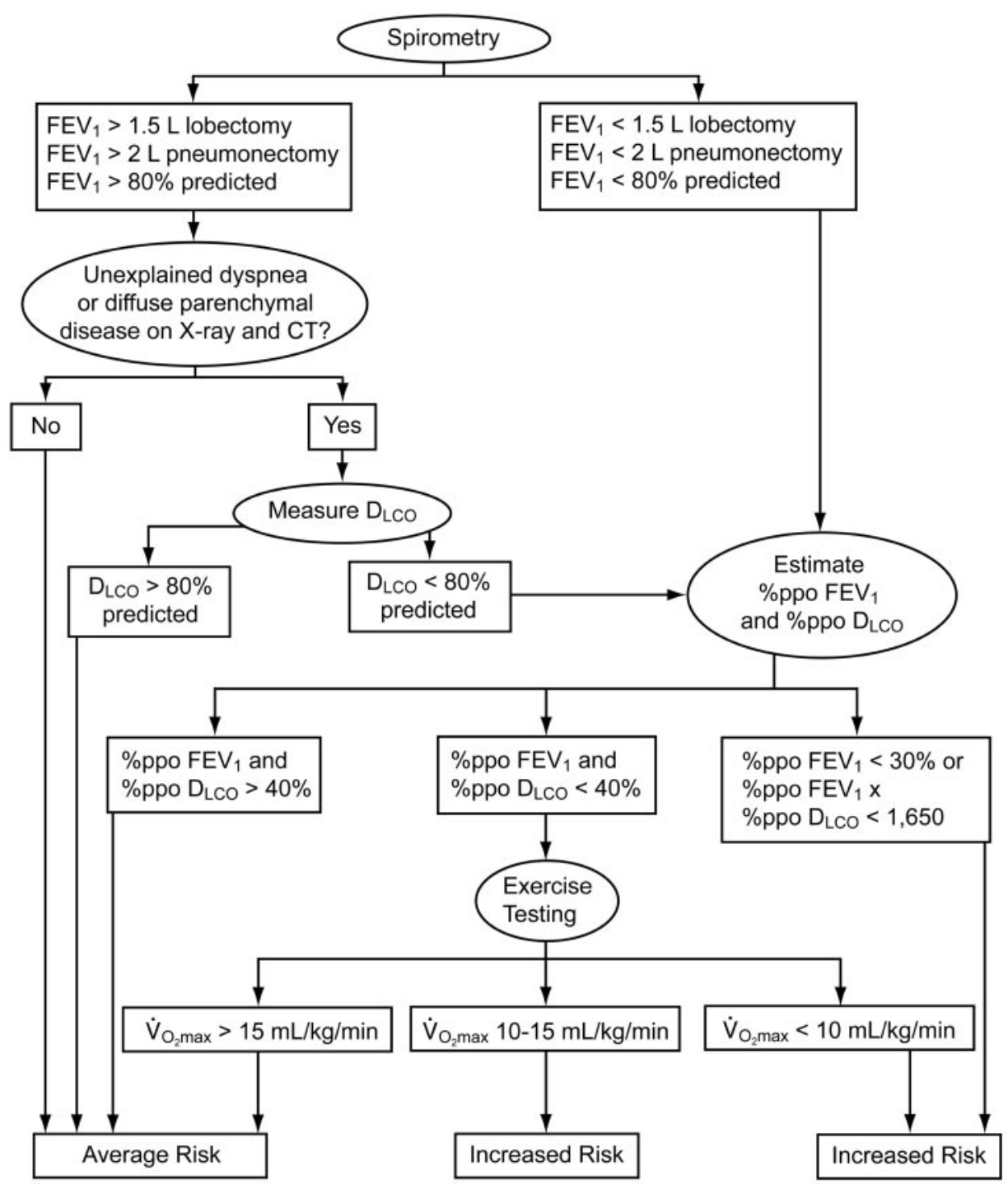

Fig. 1. Recommended algorithm for preoperative spirometric evaluation of candidates for lung resection. In this algorithm, "\%ppo" refers

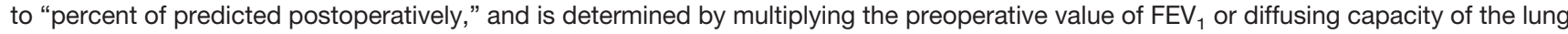
for carbon monoxide $\left(D_{\mathrm{LCO}}\right)$ by the percent of lung predicted to be intact after surgery, then converted to percent of predicted using standard equations. (From Reference 2, with permission.)

went on to comment that "consensus exists regarding the value of spirometry before lung resection...., [but] its value before extrathoracic surgery ... remains unproven." And "finally, the data do not suggest a prohibitive spirometric threshold below which the risks of surgery are unacceptable. Therefore, spirometry should be reserved for patients who are thought to have undiagnosed chronic obstructive pulmonary disease."

The use of pulmonary function testing for the prediction of risk in the development of pulmonary toxicity from chemotherapeutic agents or radiation therapy has not been studied critically. Part of the reason for the lack of extensive research in this area includes unavailability of uni- versal criteria for the diagnosis of pulmonary toxicity, the small number of patients who develop pulmonary toxicity while receiving these therapies, and the development of asymptomatic or reversible toxicity that goes unrecognized. The majority of studies evaluating both chemotherapyinduced pulmonary toxicity and radiation-induced pulmonary toxicity are case series, which document the effects and/or sequelae of therapy, not the prediction of risk. Those that attempt to do so have very small numbers and reveal conflicting results. While some suggest that pulmonary function testing is helpful in predicting toxicity, ${ }^{10,11}$ others suggest the opposite. ${ }^{12-16}$ It appears that because decreases in PFTs can occur with either chemotherapy or radiation 


\section{What Is the Role of PFTs in Monitoring Adverse Effects?}

Table 1. Proposed Lung-Volume-Reduction Surgery Criteria

\begin{tabular}{|c|c|c|}
\hline Criteria & Good Candidates & Poor Candidates \\
\hline $\begin{array}{l}\text { History and physical } \\
\text { examination }\end{array}$ & $\begin{array}{l}\text { Age }<75 \text { years } \\
\text { Emphysema by clinical evaluation } \\
\text { Ex-smoker }>4 \text { months* } \\
\text { Clinically stable on no more than } 20 \mathrm{mg} \text { prednisone daily } \\
\text { Significant functional limitation after } 6-12 \text { weeks of } \\
\text { pulmonary rehabilitation on optimal medical therapy } \\
\text { Demonstrated adherence to medical regimen }\end{array}$ & $\begin{array}{l}\text { Age } \geq 75 \text { years } \\
\text { History of recurrent bronchial infections with increased } \\
\text { sputum production } \\
\text { Cardiovascular comorbidities, including significant } \\
\text { coronary artery disease, recent myocardial infarction, } \\
\text { congestive heart failure, or uncontrolled hypertension } \\
\text { or arrhythmias } \\
\text { Pulmonary hypertension at rest } \\
\text { Nonpulmonary comorbidities causing significant } \\
\text { functional limitation (morbid obesity } \dagger \text { ) or that could } \\
\text { limit survival (eg, cancer) } \\
\text { History of thoracic surgery or chest wall deformity that } \\
\text { could interfere with pulmonary resection }\end{array}$ \\
\hline $\begin{array}{l}\text { Laboratory } \\
\text { evaluation }\end{array}$ & $\begin{array}{l}\text { Post-bronchodilator } \mathrm{FEV}_{1} \leq 45 \% \text { predicted for all ages } \\
\text { and } \geq 15 \% \text { if age } \geq 70 \text { years } \\
\text { Hyperinflation demonstrated by total lung capacity } \\
\quad \geq 100 \% \text { predicted and residual volume } \geq 150 \% \\
\text { predicted } \\
\text { Post-rehabilitation 6-minute walk distance }>140 \mathrm{~m} \\
\text { Low } \ddagger \text { post-rehabilitation exercise capacity (demonstrated by } \\
\text { maximal achieved cycle ergometry watts) } \\
\text { High-resolution computed tomogram demonstrating } \\
\text { bilateral severe emphysema, ideally with upper-lobe } \\
\text { predominance }\end{array}$ & $\begin{array}{l}\mathrm{FEV}_{1} \leq 20 \% \text { predicted and either diffusing capacity } \\
\left(\mathrm{D}_{\mathrm{LCO}}\right) \leq 20 \% \text { predicted or homogeneous distribution } \\
\text { of emphysema on high-resolution computed tomogram } \\
\text { Non-upper-lobe distribution of emphysema with high } \ddagger \\
\text { exercise capacity post-rehabilitation (demonstrated by } \\
\text { maximal achieved cycle ergometry watts) } \\
\text { Significant pleural or interstitial changes on high-resolution } \\
\text { computed tomogram }\end{array}$ \\
\hline \multicolumn{3}{|c|}{$\begin{array}{l}\text { * Plasma continine level } \leq 13.7 \mathrm{ng} / \mathrm{mL} \text { (or arterial carboxyhemoglobin } \leq 2.5 \% \text { if using nicotine products) is considered evidence that the patient is a nonsmoker. } \\
\text { † Body mass index }>31.1 \mathrm{~kg} / \mathrm{m}^{2}(\mathrm{men}) \text { or }>32.3 \mathrm{~kg} / \mathrm{m}^{2} \text { (women) is considered evidence of morbid obesity. } \\
\text { † Low exercise capacity is defined as a post-rehabilitation maximal work load at or below the sex-specific } 40 \text { th percentile }(25 \mathrm{~W} \text { for women and } 40 \mathrm{~W} \text { for man); high exercise capacity is defined as } \\
\text { a work load above this threshold. } \\
\text { (From Reference } 5 \text {, with permission.) }\end{array}$} \\
\hline
\end{tabular}

therapy, the medical community associates these changes with poorer outcomes. We assume that finding these decrements earlier and discontinuing therapy are associated with improved outcomes, especially in patients with pre-existing lung disease. However, it may be that in some patients, the decrease in spirometry or $\mathrm{D}_{\mathrm{LCO}}$ is an expected temporary outcome, and may abate with ongoing therapy. Perhaps there needs to be a threshold value included in the definition of pulmonary toxicity similar to liver function tests in isonicotinylhydrazine (INH, also known as isoniazid) therapy for latent tuberculosis infection, below which chemo or radiation therapy should be stopped. ${ }^{17}$ This would prevent premature stoppage of therapy at the first sign of decreased pulmonary function and allow for resolution of temporary abnormalities. Nonetheless, there does not appear to be good evidence that, in these 2 groups of patients, pulmonary complications can be reliably predicted from pre-therapeutic pulmonary function testing, or that early detection affects outcomes

In summary, there is substantial support for the use of spirometry in predicting risk for resectional lung surgery for lung cancer and COPD. In other types of non-thoracic surgery, as well as prediction of risk from chemotherapy or radiation therapy, the utility of pulmonary function testing remains to be determined.

\section{What Is the Role of Spirometry and $\mathrm{D}_{\mathrm{LCO}}$ in Hospitalized Patients?}

The availability and relative ease of performing officebased spirometry have led to increased awareness and use of this diagnostic modality in the out-patient setting. As patient care continues to shift from a hospital-based focus to the out-patient setting, this trend will undoubtedly continue. Along with this trend may come increased scrutiny of the value of in-patient pulmonary function testing. As of now, the number of PFTs performed on in-patients does not appear to be decreasing in many hospitals. But as more healthcare providers become aware of the available evidence-based literature, and as the amount of this data increases, pulmonary function testing on hospitalized patients will likely decrease.

In acutely ill patients requiring hospitalization, the use of pulmonary function testing is being dictated more and more by clinical practice guidelines and hospital standard 


\section{What Is the Role of PFTs in Monitoring Adverse Effects?}

operating procedures. This is especially the case in the 3 most common pulmonary causes for hospitalization: pneumonia, COPD, and asthma. ${ }^{18}$ For in-hospital management of community-acquired pneumonia, therapy is focused on etiology, already identified underlying risk factors, and appropriate choice of antibiotics. Although not critically evaluated, knowledge of the patient's acute pulmonary function has little or no impact on any of these important decisions. Understandably, the most recent Infectious Diseases Society of America/American Thoracic Society consensus guidelines on the management of community-acquired pneumonia in adults contain no recommendations for the performance of spirometry in hospitalized patients with pneumonia. ${ }^{19}$

One might imagine that if spirometry was going to be useful, it would be useful in the acute management of obstructive lung disease. Management of COPD is addressed in 2 separate, widely used guidelines. Yet the well respected American Thoracic Society/European Respiratory Society standards for the diagnosis and management of patients with COPD, published in 2004, contains no recommendations for the use of spirometry in determination of need for hospitalization, as a guide to treatment, as an indicator of need for intensive care monitoring, as a criteria for hospital discharge, or during follow-up. ${ }^{20}$ On the other hand, the recently updated Global Initiative for Chronic Obstructive Lung Disease (GOLD) document states that assessment of a COPD exacerbation should include the severity of the $\mathrm{FEV}_{1}{ }^{21}$ If severe, hospital assessment or admission are recommended. However, these recommendations are not referenced, and no additional guidance is provided regarding how to utilize these spirometric data once they are obtained. In these same guidelines, spirometry is not used as a guide to therapy, an indicator for intensive care monitoring/assisted ventilation, or as a criteria for hospital discharge. And, although measurement of $\mathrm{FEV}_{1}$ is recommended as an item to be assessed at the follow-up visit, once again, no specifics are provided on how to use the $\mathrm{FEV}_{1}$ to guide therapy. A systematic review of literature addressing adherence to the GOLD guidelines, by Lodewijckx and colleagues, found that spirometry was performed in only $12 \%$ to $18 \%$ of COPD patients hospitalized with COPD exacerbations. ${ }^{22}$ It would appear that clinicians have either not read the guidelines, are following the ATS/ERS recommendations, or are skeptical of the value of spirometry in these patients altogether.

Management of asthma exacerbations requiring hospital-based care are also addressed in 2 sets of guidelines. The updated Global Initiative for Asthma (GINA) document strongly recommends functional assessments (peak expiratory flow [PEF] or $\mathrm{FEV}_{1}$ ) of exacerbation severity, with further interval measurements until the patient has responded to treatment in the emergency department. ${ }^{23}$
This document uses pretreatment PEF or $\mathrm{FEV}_{1}<25 \%$ predicted or personal best, or those with a post-treatment PEF or $\mathrm{FEV}_{1}<40 \%$ predicted as a cutoff for patients who "usually require hospitalization." Further cutoffs of posttreatment lung function of $40-60 \%$ predicted for discharge with "adequate follow-up" and post-treatment lung function $\geq 60 \%$ predicted for discharge are proposed. All of these recommendations are unreferenced. Furthermore, no mention is made of the utility for spirometry during the in-patient management phase of asthma exacerbations.

The National Heart, Lung, and Blood Institute, National Asthma Education and Prevention Program Expert Panel Report 3: Guidelines for the Diagnosis and Management of Asthma Full Report, published in 2007, states that FEV and PEF are indicated for both emergency department and hospital-based care. ${ }^{24}$ Furthermore, FEV $_{1}$ measurements are "preferable," if they are readily available. The document recommends that $\mathrm{FEV}_{1}$ or PEF are measured at admission, 15-20 minutes after bronchodilator therapy during the acute phase (presumably in the emergency department), and at least daily afterwards. Lastly, $\mathrm{FEV}_{1}$ or PEF values $<25 \%$ of predicted that improve $<10 \%$ after treatment are considered "potential" indicators for intensive care unit admission. Just as in the GINA guidelines, these values are consensus expert opinions, and no supporting references are provided.

There do not appear to be any studies evaluating the use of spirometry in hospitalized asthmatic patients. However, in 2010 Fitzgerald and colleagues, using an Internet-based survey, evaluated the use of pulmonary function testing in the emergency departments of hospitals in 7 countries. ${ }^{25}$ Based on the responses of 298 healthcare providers and 1,078 patients, ages 15 to 70 , the authors found that among patients who underwent pulmonary function testing, only $11 \%$ had $\mathrm{FEV}_{1}, 12 \%$ had both PEF and $\mathrm{FEV}_{1}$, and the rest had only PEF measured. Forty-four percent of patients with moderate or severe exacerbations did not have any spirometric testing performed. Once again, it appears clinicians either have not read the asthma guidelines or they do not agree with them.

In summary, use of spirometry in the management of exacerbations of asthma, both in the emergency department and in the hospital, is favored. PEF is the preferred spirometric measurement of clinicians taking care of acute asthmatics, perhaps because it is easy to perform and inexpensive. The recommendations for use of spirometry in managing hospital-based COPD are mixed. Lastly, there appears to be no role for spirometry in the management of hospitalized patients with acute pulmonary infections. Until these questions are further addressed thoroughly, thus providing evidence-based guidance, the medical community will continue relying on consensus expert opinion. 


\section{What Is the Role of PFTs in Monitoring Adverse Effects?}

\section{Do Physicians Really Alter Treatment and/or Surgery Based on the Results of PFTs?}

Many healthcare providers acknowledge that spirometry is a factor in their decision-making processes. However, very few studies have looked at this question, and none has done so in a rigorous manner. Yawn and colleagues evaluated the effect of spirometry on pharmacologic and nonpharmacologic changes in the management of 382 patients with diagnoses of asthma or COPD over the age of 7 years old, from 12 family medicine practices in the United States. ${ }^{26}$ Using a before-and-after quasiexperimental design, physicians were presented with the results of spirometry after they had made an initial decision regarding their patient's management. The authors found that in $48 \%$ of cases $(n=182)$, physicians changed their management plans based on the results of spirometry. The most common medication changes $(n=107)$ were addition of a new drug (44\%), or an increase in dose of a current drug $(39 \%)$. Non-medication changes $(n=75)$ were evenly distributed among smoking cessation, repeating spirometry, ordering additional diagnostic tests, or planning more frequent follow-up visits. Reassessment of the diagnosis $(15 \%)$ or referral to a pulmonologist/cardiologist also occurred with similar frequency (13\%). The authors concluded that "spirometry results [do] modify care."

In a similar Canadian study cited by these authors, Dales and colleagues reported their findings in a total of 1,034 primary care patients. ${ }^{27}$ Their physicians were asked, prior to and following spirometry, if they believed air flow obstruction was present and if knowledge of spirometry would change their management. A follow-up chart review was performed 6 months after this initial visit to identify actual medication changes. The authors found that physicians stated that they would alter their management in $15 \%$ of patients based upon the new information. At the 6 month follow-up, only $8 \%$ of the patients had a documented change in pulmonary medications. The authors also concluded that screening spirometry influenced physician's management plans. In the former study, in which the majority of patients had asthma, the addition of spirometry resulted in improved adherence to guidelines. These guidelines incorporate spirometric values into their recommendations, both for classification of asthma severity and also for medication changes. However, it is not clear whether these changes resulted in improved outcomes, since this was not reported. This is also the case in the second study. As MacIntyre points out, "using spirometry to screen for COPD in asymptomatic populations can be problematic, and the effects of screening spirometry on outcomes have yet to be determined. The value of spirometry is increased when it is of good quality, is interpreted properly, and used in high-risk populations as a case-finding rather than a screening tool." 28 Lastly, a retrospective cohort study evaluating the use of upright and supine spirometry prior to surgery for anterior mediastinal masses, which is recommended for all of these patients in anesthesiology literature, ${ }^{29-31}$ was ordered in only $33 \%$ of cases. ${ }^{32}$ Even though spirometry was suggestive of possible upper-airway obstruction in $11 \%$ of patients, anesthetic approach was not altered and no complications occurred.

Therefore, when spirometry is performed as recommended in appropriate patient populations, changes in management and improved outcomes are possible. However, much more data are needed prior to accepting the premise that physicians alter their practice patterns based upon PFTs, or that these alterations improve outcomes.

\section{What Is the Evidence Base for Using PFTs for Priority Listing for Solid Organ Transplantation (Kidney, Liver, Lung)?}

The United Network for Organ Sharing, based in Richmond, Virginia, has administered the Organ Procurement and Transplantation Network under contract with the Health Resources and Services Administration of the United States Department of Health and Human Services since 1986. According to federal law, all United States transplant centers and organ procurement organizations must be members of the Organ Procurement and Transplantation Network to receive Medicare funds.

\section{Lung Transplantation}

Since 2005, for patients aged 12 and older, the Organ Procurement and Transplantation Network has used 3 factors to determine priority for receiving a lung transplant: an individualized lung allocation score, blood type, and geographic distance between the candidate and lung donor's hospitals. The raw lung allocation score takes into account measures of transplant benefit and wait-list urgency. This score is then normalized to a score of $0-100 .{ }^{33}$ Higher priority is given to patients with higher lung allocation score. Factors involved in the lung allocation score include FVC (\% predicted), pulmonary artery systolic pressure, supplemental $\mathrm{O}_{2}$ requirement at rest, age, body mass index, insulin-dependent diabetes, functional status (New York Heart Association class), 6-min walk distance, assisted ventilation, pulmonary capillary wedge pressure, mean pulmonary artery pressure, $\mathrm{P}_{\mathrm{CO}_{2}}$, serum creatinine, and diagnosis. ${ }^{34}$ All of these variables were derived from the United Network for Organ Sharing lung transplant list patient population, and published as a series of abstracts between 2001 and 2003. ${ }^{35,36}$ Apparently, these data have never been published in their entirety in a medical journal. Given the importance of the lung allocation score and its widespread use, the methods and statistics used to derive these variables must be assumed to be valid. Of note, 


\section{What Is the Role of PFTs in Monitoring Adverse Effects?}

although $\mathrm{FEV}_{1}$ is a significant predictor of wait-list mortality and outcome among patients with cystic fibrosis, it was not one of the variables identified by the above-mentioned analyses. This was postulated to have occurred because of the narrow range of percent of predicted $\mathrm{FEV}_{1}$ values in this subset of lung transplant patients.

Other international guidelines for selection of lung transplant candidates, from the Pulmonary Scientific Council of the International Society for Heart and Lung Transplantation, readily acknowledge that "there are no prospective, randomized, well powered studies in lung transplantation to support [their] recommendations," and that their guidelines are "a combination of recommendations based on small and/or retrospective and/or registry studies, and expert opinion consensus." 37 Nonetheless, this extensive document includes disease-specific recommendations, many of which include measures of pulmonary function. Those that do include COPD (BODE [body mass index, air-flow obstruction, dyspnea, exercise capacity] index, $\mathrm{FEV}_{1}$, $\left.\mathrm{D}_{\mathrm{LCO}}\right)$; cystic fibrosis $\left(\mathrm{FEV}_{1}\right)$; idiopathic pulmonary fibrosis $\left(\mathrm{D}_{\mathrm{LCO}}, \mathrm{FVC}\right.$, desaturation on 6MWT); pulmonary artery hypertension (6MWT distance); lymphangioleiomyomatosis (severe impairment in lung function and exercise capacity [eg, maximum oxygen uptake $<50 \%$ predicted]); and pulmonary Langerhans cell histiocytosis (severe impairment in lung function and exercise capacity). The use of the BODE index when considering lung transplantation in COPD is logical and should hasten the development of measures of lung function that incorporate multiple important elements of pulmonary function for making critical decisions. The index consists of body mass index, degree of air flow obstruction ( $\%$ predicted $\mathrm{FEV}_{1}$ ), the degree of dyspnea (modified Medical Research Council dyspnea scale), and exercise capacity (6-min walk distance), and was derived from a cohort of 207 patients with COPD. Subsequently, it was prospectively validated as a predictor of pulmonary and all-cause mortality in 625 COPD patients. ${ }^{38}$ This multi-dimensional assessment tool has been recently found to strongly predict survival in COPD patients after LVRS, ${ }^{39}$ but has yet to be found as a predictor of post-transplant mortality risk. ${ }^{40}$ Nonetheless, use of these types of indices allows incorporation of functional assessments of lung function and systemic effects of underlying lung diseases into more complete tools for improving decision making. Further development and use of such comprehensive tools in studying the role of PFTs in monitoring adverse effects can only lead to better models for predicting risk.

\section{Kidney and Liver Transplantation}

Allocation of organs to candidates for kidney transplant uses only glomerular filtration rate and need for dialysis as determinants. Liver transplantation allocation is based on
Model For End-Stage Liver Disease (MELD) scores. These scores are determined from serum bilirubin, serum creatinine, and the international normalized ratio (INR). In neither case does transplantation depend on measures of pulmonary function. ${ }^{34}$

\section{Summary}

A large body of evidence exists favoring the use of PFTs for prediction of risk related to lung surgery (lung resection, LVRS, lung transplantation). It is also likely that spirometry may be useful in guiding decisions for outpatients with known or suspected lung disease. However, there is no definitive evidence to suggest that spirometry is useful in predicting risk from non-thoracic surgery, chemotherapy, or radiation therapy. In addition, in most cases, preoperative spirometry ordered within 24 hours of surgery has little chance of substantially altering decision making in any surgical procedure.

\section{REFERENCES}

1. Hayhurst MD. Preoperative pulmonary function testing. Respir Med 1993;87(3):101-103.

2. Colice GL, Shafazarand S, Griffin JP, Keenan R, Bolliger CT. Physiologic evaluation of the patient with lung cancer being considered for resectional surgery: ACCP evidence-based clinical practice guidelines, 2nd edition. Chest 2007;132(3 Suppl):161S-177S.

3. Armstrong P, Congleton J, Fountain SW, Jagoe T, McAuley DF, MacMahon J, et al; British Thoracic Society and Society of Cardiothoracic Surgeons of Great Britain and Ireland Working Party. Guidelines on the selection of patients with lung cancer for surgery. Thorax 2001;56(2):89-108.

4. Miller JI Jr. Physiologic evaluation of pulmonary function in the candidate for lung resection. J Thorac Cardiovasc Surg 1993;105(2): 347-351.

5. DeCamp MM Jr, Lipson D, Krasna M, Minai OA, McKenna RJ Jr, Thomashow BM. The evaluation and preparation of the patient for lung volume reduction surgery. Proc Am Thorac Soc 2008;5(4):427431.

6. National Emphysema Treatment Trial Research Group. Patients at high risk of death after lung- volume-reduction surgery. N Engl J Med 2001;345(15):1075-1083.

7. Fishman A, Martinez F, Naunheim K, Piantodosi S, Wise R, Ries A, et al; National Emphysema Treatment Trial Research Group. A randomized trial comparing lung-volume-reduction surgery with medical therapy for severe emphysema. N Engl J Med 2003;348(21): 2059-2073.

8. Smetana GW, Lawrence VA, Cornell JE; American College of Physicians. Preoperative pulmonary risk stratification for noncardiothoracic surgery: systematic review for the American College of Physicians. Ann Intern Med 2006;144(8):581-595.

9. Qaseem A, Snow V, Fitterman N, Hornbake ER, Lawrence VA, Smetana GW, et al; Clinical Efficacy Assessment Subcommittee of the American College of Physicians. Risk assessment for and strategies to reduce perioperative pulmonary complications for patients undergoing noncardiothoracic surgery: a guideline from the American College of Physicians. Ann Intern Med 2006;144(8):575-580.

10. Wolkowicz J, Sturgeon J, Rawji M, Chan CK. Bleomycin-induced pulmonary function abnormalities. Clin Chest Med 1992;101(1):97101. 


\section{What Is the Role of PFTs in Monitoring Adverse Effects?}

11. Lind PA, Marks LB, Jamieson TA, Carter DL, Vredenburgh JJ, Folz RJ, Prosnitz LR. Predictors for pneumonitis during locoregional radiotherapy in high-risk patients with breast carcinoma treated with high-dose chemotherapy and stem-cell rescue. Cancer 2002;94(11): 2821-2829.

12. Lucraft HH, Wilkinson PM, Stretton TB, Read G. Role of pulmonary function tests in the prevention of bleomycin pulmonary toxicity during chemotherapy for metastatic testicular teratoma. Eur J Cancer Clin Oncol 1982;18(2):133-139.

13. Van Barneveld PW, van der Mark TW, Sleijfer DT, Mulder NH, Koops HS, Sluiter HJ, Peset R. Predictive factors for bleomycininduced pneumonitis. Am Rev Respir Dis 1984;130(6):1078-1081.

14. Bell MR, Meredith DJ, Gill PG. Role of carbon monoxide diffusing capacity in the early detection of major bleomycin-induced pulmonary toxicity. Aust N Z J Med 1985;15(2):235-240.

15. Tsougos I, Nilsson P, Theodorou K, Kjellen E, Ewers SB, Jarlman $\mathrm{O}$, et al. NTCP modelling and pulmonary function tests evaluation for the prediction of radiation induced pneumonitis in non-small-cell lung cancer radiotherapy. Phys Med Biol 2007;52(4):1055-1073.

16. Vagane R, Bruland OS, Fossa SD, Olsen DR. Radiological and functional assessment of radiation-induced pulmonary damage following breast irradiation. Acta Oncol 2008;47(2):248-254.

17. American Thoracic Society. Targeted tuberculin testing and treatment of latent tuberculosis infection. Am J Respir Crit Care Med 2000;161(Suppl):S221-S247.

18. Centers for Disease Control and Prevention. Number of discharges from short-stay hospitals by first-listed diagnosis and age: United States, 2007. http://www.cdc.gov/nchs/data/nhds/3firstlisted/ 2007first3_numberage.pdf. Accessed October 31, 2011

19. Mandell LA, Wunderink RG, Anzueto A, BartlettJG, Campbell GD, Dean NC, et al; Infectious Disease Society of America; American Thoracic Society. IDSA/ATS consensus guidelines on the management of community-acquired pneumonia in adults. Clin Infect Dis 2007;44(Suppl 2):S27-S72

20. Celli BR, MacNee W; ATS/ERS Task Force. Standards for the diagnosis and treatment of patients with COPD: a summary of the ATS/ERS position paper. Eur Respir J 2004;23(6):932-946.

21. The Global Initiative for Chronic Obstructive Lung Disease. http:// www.goldcopd.org. Accessed October 31, 2011.

22. Lodewijckx C, Sermeus W, Vanhaecht K, Panella M, Deneckere S, Leigheb F, Decramer M. Inhospital management of COPD exacerbations: a systematic review of the literature with regard to adherence to international guidelines. J Eval Clin Pract 2009;15(6):11011110 .

23. The Global Initiative for Asthma. http://www.ginasthma.org. Accessed October 31, 2011.

24. US Department of Health \& Human Services; National Heart, Lung and Blood Institute. Guidelines for the diagnosis and management of asthma (EPR-3). http://www.nhlbi.nih.gov/guidelines/asthma. Accessed October 31, 2011

25. Fitzgerald JM, O’Byrne PM, McFetridge JT, Demuth D, Allen-Ramey FC. Pulmonary function testing in the emergency department and medications prescribed at discharge: results of the Multinational Acute asthma Management, Burden, and Outcomes (MAMBO) study. Prim Care Respir J 2010;19(2):155-162.

26. Yawn BP, Enright PL, Lemanske RF Jr, Israel E, Pace W, Wollan P, Boushey H. Spirometry can be done in family physicians' offices and alters clinical decisions in management of asthma and COPD. Chest 2007;132(4):1162-1168.

27. Dales RE, Vandemheen KL, Clinch J, Aaron SD. Spirometry in the primary care setting: influence on clinical diagnosis and management of airflow obstruction. Chest 2005;128(4):2443-2447.

28. MacIntyre NR, Selecky PA. Is there a role for screening spirometry? Respir Care 2010;55(1):35-42.

29. Benumof JL, Alfery DD. Anesthesia for thoracic surgery. In: Miller RD, editor. Anesthesia, 4th edition. New York: Churchill Livingstone; 1994:970.

30. Eisenkraft JB, Cohen E, Neustein SM. Anesthesia for thoracic surgery. In: Barash PG, Cullen BF, Stoelting RK, editors. Clinical anesthesia, 3rd edition. Philadelphia: Lippincott-Raven; 1997:790.

31. Neuman GG, Weingarten AE, Abramowitz RM, Kushins LG, Abramson AL, Ladner W. The anesthetic management of the patient with an anterior mediastinal mass. Anesthesiology 1984;60(2):144-147.

32. Hnatiuk OW, Corcoran PC, Sierra A. Spirometry in surgery for anterior mediastinal masses. Chest 2001;120(4):1152-1156.

33. Egan TM, Kotloff RM. Pro/con debate: lung allocation should be based on medical urgency and transplant survival and not on waiting time. Chest 2005;128(1):407-415.

34. US Department of Health \& Human Services; Health Resources and Services Administration; Organ Procurement and Transplantation Network. http://optn.transplant.hrsa.gov. Accessed October 31, 2011.

35. Egan TM, Bennett LE, Garrity ER, Grover FL, Ring WS, Robbins $\mathrm{RC}$, et al. Predictors of death on the UNOS lung transplant waiting list: results of a multivariate analysis. J Heart Lung Transplant 2001; 20(2):242.

36. Egan TM, Bennett LE, Garrity ER, Grover FL, et al. Are there predictors of death at the time of listing for lung transplant. J Heart Lung Transplant 2002;21(1):154.

37. Orens JB, Estenne M, Arcasoy S, Conte JV, Corris J, Egan JJ, et al. International Guidelines for the selection of lung transplant candidates: 2006 update. A consensus report from the Pulmonary Scientific Council of the International Society for Heart and Lung Transplantation. J Heart Lung Transplant 2006;25:745-755.

38. Celli BR, Cote CG, Marin JM, Casanova C, Montes de Oca M, Mendez RA, et al. The body-mass index, airflow obstruction, dyspnea, and exercise capacity Index in chronic obstructive pulmonary disease. N Engl J Med 2004;350(10):1005-1012.

39. Imfeld S, Bloch KE, Weder W, Russi EW. The BODE index after lung volume reduction surgery correlates with survival. Chest 2006; 129(4):873-878.

40. Lahzami S, Bridevaux PO, Soccal PM, Wellinger J, Robert JH, Ris HB, Aubert JD. Survival impact of lung transplantation for COPD. Eur Respir J 2010;36(1):74-80.

\section{Discussion}

Culver: When I reviewed this preoperative literature about 10 years ago I was frustrated by some of the same things I think you were, particularly the surgical studies. When you pre-set a criteria based on some prior data, observations, or personal experience and then find that people above that do OK, it doesn't tell you that people a little bit below that might've done OK too. That's what we really need: to look at that marginal group and see how they do. There are a few anecdotal reports of people who have taken some marginal individuals to surgery, but one doesn't know how they were selected, and they tend to report only positive outcomes in those cases, so you can't use them for risk assessment. You get a one-sided picture and it doesn't really answer as many questions as you'd like.The NETT study, ${ }^{1}$ as you showed, was one place where they, sort of accidentally, cast the net a little too broad and then did find by 


\section{What Is the Role of PFTs in Monitoring Adverse Effects?}

objective outcome a high risk group, ${ }^{2}$ and that's obviously a much more valuable experience, because then you really do define high risk. But it does mean that some people have to operate on those patients with high risk and then report those outcomes.

1. Benzo R, Farrell MH, Chang CC, Martinez FJ, Kaplan R, Reilly J, et al; NETT Research Group. Integrating health status and survival data: the palliative effect of lungvolume-reduction surgery. Am J Respir Crit Care Med 2009;180(3):239-246.

2. National Emphysema Treatment Trial Research Group. A randomized trial comparing lung-volume-reduction surgery with medical therapy for severe emphysema. N Engl J Med. 2003;348:2059-2073.

Hnatiuk: You're absolutely right. There are anecdotal case reports where LVRS has been done on high-risk patients and they did just fine.

Kaminsky: I just wanted to make the comment that at our place we use exercise testing to help stratify patients for lung resection surgery, for tumor removal, et cetera. The surgeons who are involved in that buy into it, but at the same time, when the numbers come out discordant from their feeling, they take the patient on a walk up and down the stairs.

Hnatiuk: There is support for stair climbing as a surrogate predictor of outcome. $^{1}$

1. Brunell A, Refal MA, Monteverde M, Borri A, Salati M, Fianchini A. Stair climbing test predicts cardiopulmonary complications after lung resection. Chest 2002; 121(4):1106-1110.

Kaminsky: There is literature on the shuttle walk in Europe that also can prognosticate. When our surgeon says, "The $\mathrm{V}_{\mathrm{O}_{2 \max }}$ was $\mathrm{X}$ and $\mathrm{I}$ know that's below the limit of $10 \mathrm{~mL} / \mathrm{kg} / \mathrm{min}$ post-op predicted, but the patient can climb three flights of stairs and I'm going to take him to surgery," you have to give the surgeon credit be- cause he's trying to do what he can to cure this stage 1 tumor.

Hnatiuk: It gets back to what Neil was saying initially, and the study that I discussed. Ultimately, it's between the thoracic surgeon and the patient, as to how much risk each one is willing to assume in a deadly disease such as lung cancer.

MacIntyre: I think I know the answer to this. You reviewed nicely that PFTs don't predict chemotherapy toxicity or radiation toxicity, which I'd certainly agree with. But I don't think you meant to imply that these aren't decent tests to monitor patients while they're on chemotherapy. Or maybe I'm misinterpreting here, because it certainly drives decisions in my place. Clinicians see diffusions start to tail off or the FVC start to fall off, they will stop or change the chemo in a heartbeat.

Hnatiuk: I agree with your statement that changes in spirometry currently drive decisions regarding radiation and chemotherapy. However, until pulmonologists design larger and better studies identifying predictors for toxicity, oncologists and radiation therapists will continue to rely on suboptimal studies to make clinical decisions. It's the best that we have right now. If you monitor everyone on therapy, you're going to find some who have decreases in their $\mathrm{D}_{\mathrm{LCO}}$. The next question has to be, does stopping make a difference? There are patients described in the literature who have decreases in $\mathrm{D}_{\mathrm{LCO}}$ but come right back to normal despite continued therapy.

MacIntyre: Maybe the reason there's only $10 \%$ lung toxicity is because it's being stopped and modified, but I agree. I don't have data that support that.

Culver: But at least some of the protocols - and these may be research protocols where they set up specific diffusing capacity criteria-there are patients who are being told, "Your diffusing capacity is less than $40 \%$ so you can't go on this protocol," and that's leading to questions about $40 \%$ of what? Do we have the right prediction reference values? And sometimes you don't even know where those numbers came from. There's a fair body of surgical literature about diffusing capacity of less than $40 \%$ in thoracic resections as well, and most of it from one group, and the papers ${ }^{1,2}$ don't mention what reference source is used for the diffusing capacity. So I don't know whether they've chosen a low one or a high one or whether the lab is calibrated to that reference set. The variability makes it a very squishy number for life-or-death decisions to be made on whether you're $38 \%$ or $42 \%$.

1. Ferguson MK, Gaissert HA, Grab JD, Sheng S. Pulmonary complications after lung resection in the absence of chronic obstructive pulmonary disease: the predicted role of diffusing capacity. J Thorac Cardiovasc Surg 2009;138(6):1297-1302.

2. Wang J, Olak J, Ferguson MK. Diffusing capacity predicts operative mortality but not long-term survival after resection for lung cancer. J Thorac Cardiovasc Surg 1999; 117(3):581-587.

MacIntyre: I have to keep driving it home, especially to the oncologists, that you've got to watch the hemoglobin. Their chemotherapy agents will knock the daylights out of the hemoglobin and can send the diffusion into the toilet only from the anemia effect. They need to understand that very carefully.

Coates: Well, they need to measure the hemoglobin before they send it to the PFT labs, so we can do some kind of correction. Frequently, they don't understand that.

Culver: We measure it in the lab. If they come for $\mathrm{D}_{\mathrm{LCO}}$, they get a finger stick.

MacIntyre: We used to do that and we got our hand slapped by CLIA 


\section{What Is the Role of PFTs in Monitoring Adverse EfFects?}

[Clinical Laboratory Improvement Act], because sampling blood is not something we're allowed to do. We've been looking at the pulse oximeter that's reported to measure total hemoglobin as perhaps a surrogate.

McCormack: Our oncologists are pretty diligent in checking hemoglobin, so, unfortunately, I would probably say if $\mathrm{D}_{\mathrm{LCO}}$ values are not corrected for hemoglobin, it's probably our lack of putting those data together rather than the lack of hemoglobins being drawn.

Coates: How good is the correction?

MacIntyre: Better than nothing.

Culver: How would we know?

MacIntyre: Exactly: how would we know? The ATS/ERS uses the Cotes formula. I agree we haven't studied it in a rigid fashion, but it's certainly better than not measuring it at all.

Salzman: We are always trying to dig up hemoglobin results to adjust our measured $\mathrm{D}_{\mathrm{LCO}}$ values, and then we come to the issue of how old can the hemoglobin test be and still be OK? So we started doing finger-stick hemoglobin in our lab at the time of measured diffusing capacity, but we've also been interested in this new Masimo device that measures noninvasive hemoglobin. I don't have any experience with whether that noninvasive hemoglobin is accurate. Does anybody here have experience with it?

Ruppel: We evaluated that device. ${ }^{1}$ We compared blood gases and the Masimo device, for hemoglobin and carboxyhemoglobin. We used 2 separate devices at the same time and we used a clinical cutoff of \pm 3 units, and looked to see if correcting by one method versus a blood oximetry would cause a difference of more than $3 \mathrm{D}_{\mathrm{LCO}}$ units in the final answer, and it did. The error when we compared the 2 methods was greater than 3 units. But don't get excited. There are caveats. We used it in a spot-check type of mode, where you put the device on, wait till it stabilizes, and take a reading. Most of the literature that we reviewed showed it being used in emergency rooms and surgery suites, where it was put on and left on long enough that perhaps it stabilized more than we would see in a 5-10-minute spotcheck situation. So there are some caveats to the data, but we decided not to use it.

1. Ruppel GL, Wilson HA, Gall VK, Hempkens JA. Multi-wavelength pulse oximeter is not suitable for adjusting $\mathrm{D}_{\mathrm{LCO}}$ measurements. Respir Care 2011;56(8):11151121. 